\title{
Combustion of Biomass as a Global Carbon Sink
}

\author{
Rowena Ball
}

\begin{abstract}
Mathematical Sciences Institute and Research School of Physics and Engineering, The Australian National University, Canberra 0200, Australia
\end{abstract}

\begin{abstract}
This commentary article highlights the important role of black carbon produced from biomass burning in the global carbon cycle. Consideration of the fundamental chemistry and thermokinetics of cellulose thermal decomposition suggests that suppression of biomass burning or biasing burning practices to produce soot-free flames must inevitably transfer more carbon to the atmosphere. A simple order-of-magnitude quantitative analysis indicates that black carbon may be a significant carbon reservoir that persists over geological time scales.
\end{abstract}

Keywords: Carbon cycle, carbon sequestration, black carbon, charcoal, biomass combustion.

A recent review by Ramanathan and Carmichael [1] focuses on the role of aerosol black carbon or soot in climate variability, with strong radiative forcing predicted. On the other hand, the global climate model used by Schmittner et al. [2] makes long-term predictions of temperature rises due to atmospheric and oceanic oxidized carbon loadings but neglects the contribution made by black carbon (charcoal and soot). However, black carbon produced as a result of biomass burning may have a role in the long-term carbon cycle that is significant both quantitatively and in terms of our response to biomass combustion and climate changes.

Black carbon is defined as the combustion product fraction that has a $\mathrm{H} / \mathrm{C}$ molar ratio $\leq 0.2$ and is thermally stable to $340^{\circ} \mathrm{C}$ in pure oxygen [3]. The production of black carbon from biomass burning is governed by the thermal decomposition (or pyrolysis) chemistry of cellulose, the major constituent of the terrestrial biomass and by far the most abundant biopolymer on earth. In Fig. (1) the key carbon reservoirs and transfer channels involved in the biomass burning cycle are schematized. Under the thermal stress of a fire the primary decomposition of cellulose yields combustible volatiles (mainly the anhydrosugar levoglucosan) and solid black carbon residue.

Crucial to the fire ecology subsystem, and to the global carbon cycle as a whole, is the competitive nature of these two processes - volatiles are produced at the expense of char and vice versa. The reciprocally linked formation of volatiles and char was first suggested formally in the work of Kilzer and Broido (1965) [4] and has been verified by numerous experiments since.

A small fraction of the hot volatile gases also condenses and dehydrates to black carbon, or soot, as indicated in the figure. During normal biomass burning conditions the volatiles oxidize to carbon dioxide, water, and other minor products (flaming combustion). Where the temperature is

*Address correspondence to this author at the Mathematical Sciences Institute and Research School of Physics and Engineering, Building 27, The Australian National University, Canberra 0200 Australia;

E-mail: Rowena.Ball@anu.edu.au

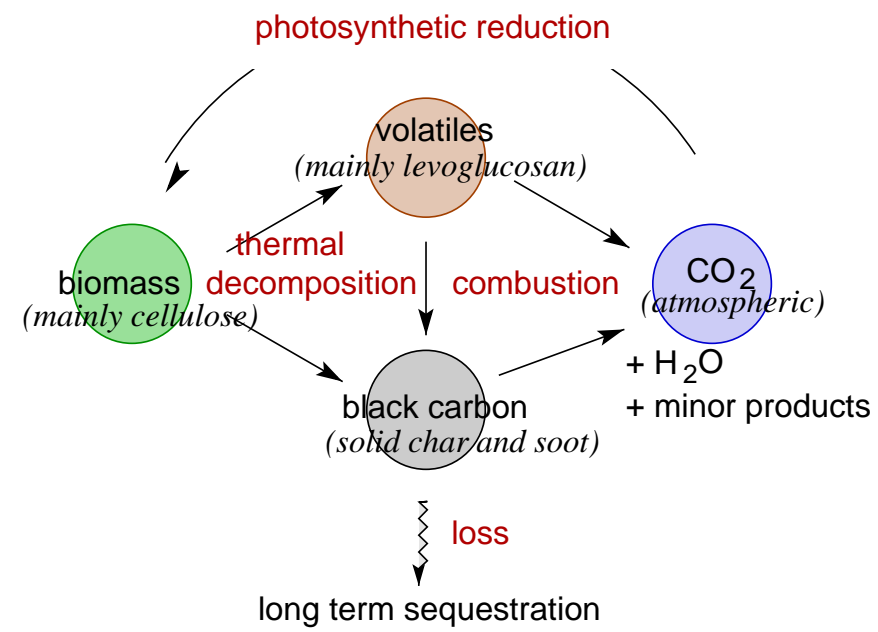

Fig. (1). In this simplified (but not inaccurate) world carbon accumulates in the long time scale (> 6000 years) reservoir of black carbon which therefore becomes a loss channel, relative to the short time scale (1-200 years) of carbon accumulation in the biomasss and atmospheric $\mathrm{CO}_{2}$ reservoirs. The processes that distribute carbon between flammable volatiles and black carbon are reciprocally linked, or competitive.

high enough a small amount of the black carbon also burns (glowing combustion), but most remains intact chemically and joins a stable pool of carbon sequestered for the long term. Thus, while the residence time of carbon in the volatiles pool is effectively zero, since volatiles are removed by combustion or condensation as soon as they are formed, the biomass and $\mathrm{CO}_{2}$ pools do not "see" any changes in the unburned black carbon pool.

What are these processes at the core of this competition, that are so important in the global carbon cycle? Cellulose thermal decomposition chemistry is complicated and not all of the reaction pathways are known, but the fundamental competing reactions that determine the bias toward charring or volatilization are exemplars of well-known nucleophilic addition chemistry. For heuristic purposes they are shown in Fig. (2) and a brief outline follows. The primary structure of cellulose consists of $\beta-1,4$ linked glucopyranose units in alternating orientation in a linear chain, a two-unit section of 
which is sketched in Fig. (2), labeled as A. Thermolysis of A yields positively charged $\mathbf{B}$ and negatively charged $\mathbf{C}$ fragments. The competing reaction steps are highlighted in the figure: the resonance-stabilized positive centre of $\mathbf{B}$ may be attacked by the hydroxyl group on C- 6 of the same unit to produce the cyclized levoglucosan end $\mathbf{D}$ or by a water molecule to produce a reactive reducing end $\mathbf{E}$. Thermolysis at the next glycosidic linkage of $\mathbf{D}$ releases the volatile levoglucosan. The species $\mathbf{E}$ undergoes subsequent dehydration, decarbonylation, aromatization, and cross-linking reactions that produce black carbon. (The negatively charged fragment $\mathbf{C}$ rapidly picks up a positive hydrogen ion to form a relatively unreactive non-reducing end $\mathbf{F}$ ).

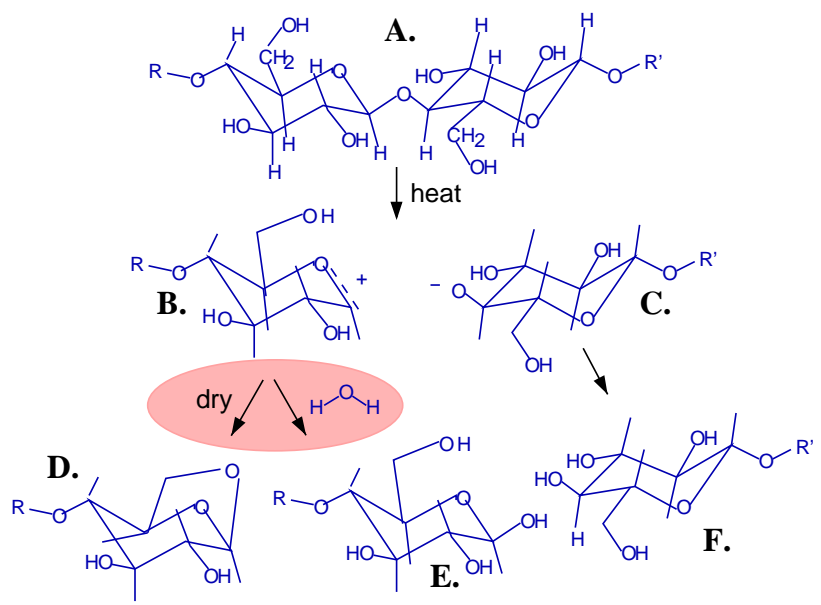

Fig. (2). Competitive nucleophilic addition chemistry at the heart of cellulose thermal decomposition. $\mathrm{R}$ and $\mathrm{R}$ ' designate the remainders of the chains on reducing and non-reducing sides of the two-unit section A. To unclutter the sketches the symbols for hydrogen atoms attached to the carbon skeleton are included only for $\mathbf{A}$.

During pyrolysis the instantaneous balance between charring and volatilization depends on the thermokinetics (or temperature dependent rates) and enthalpies of the competing processes. In Fig. (3) the governing thermal and chemical feedbacks are indicated. The dehydration reactions essential to char formation have low activation energy $\left(\sim 110-200 \quad \mathrm{~kJ} \mathrm{~mol}^{-1}\right)$ and occur at relatively low temperatures as the cellulose substrate heats. The water produced can act as an autocatalyst, inhibiting volatilization and biasing the competition toward charring. However, the

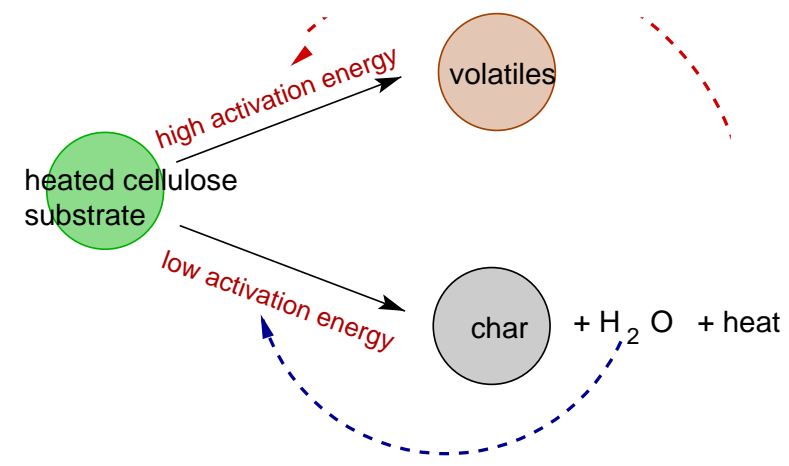

Fig. (3). Chemical and thermal feedbacks, indicated by dotted arrows, govern the competition between charring and volatilization pathways. charring reactions are bond-forming and exothermic $(\Delta H$ $\approx-2000 \mathrm{Jg}^{-1}$ of char formed). This heat promotes the temperature sensitive, high activation energy $(\sim 200-240 \mathrm{~kJ}$ $\mathrm{mol}^{-1}$ ), volatilization reactions, which begin to take over. But volatilization is endothermic $\left(\Delta H \approx 540 \mathrm{Jg}^{-1}\right.$ of volatiles formed) so in the absence of an alternative heat source such as combustion the reaction self-damps, thus switching the reaction field again to the charring pathway. Under appropriate conditions fires can be observed to flicker and fluctuate between these two pathways. More details on the chemistry and competitive thermokinetics of cellulose pyrolysis can be found in the works of Ball et al. [5-7] and references therein.

The black carbon that is ultimately formed from reducing end fragments $\mathbf{E}$ in Fig. (2) has a polymeric aromatic to crystalline graphitic structure that is highly resistant to chemical, photochemical, and enzyme attack. It is believed to have accumulated in marine sediments over gelogical time, indicating that it is a long-term carbon sink [3, 8], although quantification of black carbon in soils and sediments has large error bars [9]. In the simplified (but not inaccurate) world of Fig. (1) the only mass loss channel is via the black carbon reservoir and any non-zero production of black carbon must inevitably result in carbon sequestration, which could become significant over cycles of burning and regrowth.

How significant is black carbon as a carbon sink? Some reasonable order-of-magnitude quantitation would be helpful, at least as a starting point. In the simplest case one assumes that burnt biomass is renewed annually. The amount of carbon stored in the atmosphere is estimated as $750 \mathrm{Gt}$ and the amount in vegetation is estimated as $610 \mathrm{Gt}$ [10]. The mass percentage of the carbon in the biomass that is burned each year is taken as 1\%. (Wirth et al. (2002) [11] estimated that $33 \%$ of net carbon gain in Siberian forests is lost to fire, so this does not seem unreasonable.) The average fraction of biomass carbon converted to black carbon during each burning cycle is taken as 5\% [12]. (Estimates in the literature range from $\sim 40 \%$ [13] to $\sim 3 \%$ [14]). After 100 years of annual burning and regrowth under these conditions the amount of black carbon produced is $30.5 \mathrm{Gt}$ and the mass of carbon in the atmosphere has been reduced by $4.1 \%$.

In this simple model the rate of production of black carbon is effectively first order in the amount of carbon in the atmospheric reservoir. The rate or time constant is $<<$ $1 \mathrm{yr}^{-1}\left(\sim 4 \times 10^{-4} \mathrm{yr}^{-1}\right)$ so that over 100 years the accumulation of black carbon is linear to a good approximation. Of course one does not expect that atmospheric $\mathrm{CO}_{2}$ would asymptote to zero, disappearing into the black carbon sink through smaller and smaller conflagrations of an ever-diminishing biomass. In reality other carbon pathways may take over. For example, we note that a) condensation and combustion of volatiles are also competing reaction paths in Fig. (1), and b) black carbon production sequesters molecular oxygen in the atmosphere [3]. Thus higher partial pressure of oxygen may favor soot reduction by biasing this secondary competition toward cleaner burning of the volatiles, resulting in a larger fraction of carbon being returned to the atmosphere as $\mathrm{CO}_{2}$. (However, lower oxygen concentrations on a warmer earth are predicted in the work of [2]). On the other hand, charring also produces water vapor. Reference to Figs. (2) and (3) 
indicates that increased concentrations of water vapour may favor the charring pathway in Fig. (1), having an autocatalytic effect provided the heat released by charring is dissipated before it switches the system to the volatilization pathway.

These hypothetical examples fall into the category of "educated conjectures" at present, but they, and this discussion as a whole, do highlight important but neglected issues regarding the crucial role played by the competitive thermal decomposition of cellulose in global carbon cycles. In summary:

1. A simple order-of-magnitude quantitative analysis indicates that black carbon may be a significant carbon reservoir that persists over geological time scales. Predictive global climate cycle models as used in [2] that neglect the production of black carbon may need significant corrections.

2. The competition between volatilization and charring in Fig. (1) that rules the thermal decomposition of cellulosic biomass can be biased one way or the other by natural events or by management or engineering practices.

3. Sequestration of biomass carbon into the stable black carbon pool is inhibited and release of $\mathrm{CO}_{2}$ by respiration is enhanced if biomass burning is suppressed.

4. On the global scale, decreased biomass burning, hotter biomass burning, and biasing burning practices (of biomass and fossil fuels) to produce soot-free flames as suggested in [1], inevitably transfer more carbon to the atmosphere at the expense of black carbon production.

Further quantification work may help to refine global climate cycle models such as that used by Schmittner et al. [2], and estimates of the effects of aerosols on climates such as those made by Ramanathan and Carmichael [1]. The black carbon issue is likely to receive more attention because increasing temperatures and temperature gradients are predicted to result in more wildfires, and people's dependence on biomass for fuel is also expected to continue increasing.

It is also interesting to ponder that the most prolific biopolymer on earth has exactly the right competitive thermokinetic and thermochemical properties to prevent it from swamping the earth, thwart the development of intolerable populations of termites (and therefore methane emissions), and provide a stable carbon sink. Its thermal decomposition and combustion behaviors should not be neglected.

\section{REFERENCES}

[1] V. Ramanathan, and G. Carmichael, "Global and regional climate changes due to black carbon", Nat. Geosci., vol. 1, pp. 221-227, March 2008.

[2] A. Schmittner, A. Oschlies, H.D. Matthews, and E.D. Galbraith, "Future changes in climate, ocean circulation, ecosystems, and biogeochemical cycling simulated for a business-as-usual $\mathrm{CO}_{2}$ emission scenario until year 4000 AD", Global Biogeochem. Cycl., vol. 22, pp. GB1013, 1-21, February 2008.

[3] T.A.J. Kuhlbusch, and P.J. Crutzen, "Towarda global estimate of black carbon in residues of vegetation fires representing a sink of atmospheric $\mathrm{CO}_{2}$ and a sourceof $\mathrm{O}_{2} "$, Global Biogeochem. Cycl., vol. 9, no. 4, pp. 491-501, September 1995.

[4] F.J. Kilzer, and A. Broido, "Speculations on the nature of cellulose pyrolysis", Pyrodynamics, vol. 2, pp. 151-163, 1965.

[5] R. Ball, A.C. McIntosh, and J. Brindley, "The role of char-forming processes in the thermal decomposition of cellulose", Phys. Chem. Chem. Phys., vol. 1, no. 21, pp. 5035-5043, September 1999.

[6] R. Ball, A.C. McIntosh, and J. Brindley, "Thermokinetic models for simultaneous reactions: a comparative study", Combust. Theor Model., vol. 3, pp. 447-468, September 1999.

[7] R. Ball, A.C. McIntosh, and J. Brindley, "Feedback processes in cellulose thermal decomposition. Implications for fire-retarding strategies and treatments", Combust. Theor. Model., vol. 8, no. 2, pp. 281-291, June 2004.

[8] C.M. Preston, and M.W.I. Schmidt, "Black (pyrogenic) carbon: a synthesis of current knowledge and uncertainties with special consideration of boreal regions", Biogeosciences, vol. 3, no. 4, pp. 397-420, September 2006.

[9] K. Hammes, M.W.I. Schmidt, R.J. Smernik, L.A. Currie, W.P. Ball, T.H. Nguyen, P. Louchouarn, S. Houel, O. Gustafsson, M Elmquist, G. Cornelissen, J.O. Skjemstad, C.A. Masiello, J. Song, P. Peng, S. Mitra, J.C. Dunn, P.G. Hatcher, W.C. Hockaday, D.M. Smith, C. Hartkopf-Froeder, A. Boehmer, B. Luer, B.J. Huebert, W. Amelung, S. Brodowski, L. Huang, W. Zhang, P.M. Gschwend, D.X. Flores-Cervantes, C. Largeau, J.N. Rouzaud, C. Rumpel, G. Guggenberger, K. Kaiser, A. Rodionov, F.J. Gonzalez-Vila, J.A. Gonzalez-Perez, J.M. de la Rosa, D.A.C. Manning, E. LopezCapel, and L. Ding, "Comparison of quantification methods to measure fire-derived (black/elemental) carbon in soils and sediments using reference materials from soil, water, sediment and the atmosphere", Global Biogeochem. Cycl., vol. 21, GB3016, August 2007.

[10] J.T. Houghton, L.G. Meiro Filho, B.A. Callander, N. Harris, A. Kattenburg, and K. Maskell, Eds., In Climate Change 1995: The science of climate change. Contribution of working group 1 to the second assessment report of the Intergovernmental Panel on Climate Change. Cambridge University Press, 1996.

[11] C. Wirth, C.I. Czimczik, and E.-D. Schulze, "Beyond annual budgets: carbon flux at different temporal scales in fire-prone Siberian Scots pine forests", Tellus B, vol. 54, pp. 611-630, November 2002.

[12] M.S. Forbes, R.J. Raison, and J.O. Skjemstad, "Formation, transformation, and transport of black carbon (charcoal) in terrestrial and acquatic ecosystems", Sci. Total Environ., vol. 370, pp. 190-206, April 2006.

[13] W. Seiler, and P. J. Crutzen, "Estimates of gross and net fluxes of carbon between the biosphere and the atmosphere from biomass burning”, Climatic Change, vol. 2, no. 3, pp. 207-247, September 1980.

[14] P.M. Fearnside, N. Leal Jr., and F.M. Fernandes, "Rainforest burning and the global carbon budget: Biomass, combustion efficiency, and charcoal formation in the Brazilian Amazon", J. Geophys. Res., vol. 98, pp. 16733-16 743, September 1993. 